\title{
0 desenvolvimento agrícola e o processo migratório no Brasil
}

\author{
Agricultural development and the migration process in Brazil \\ El desarrollo agrícola y el proceso de migración en Brasil
}

Claudia Maria PrudênciodeMera*

\section{Resumo}

$\mathrm{O}$ meio rural sempre esteve presente nas discussões sobre o desenvolvimento por sua participação econômica, pela organização da sua matriz produtiva ou, ainda, devido aos entraves que a atividade possa representar para o restante da economia. Neste estudo, discute-se o aspecto demográfico e o processo migratório, enfatizando o contexto brasileiro. Pode-se dizer que a discussão sobre a temática da diminuição da população rural inicia-se no período que precede as políticas nacional-desenvolvimentistas e do esgotamento do modelo agroexportador brasileiro baseado no café. Estuda-se, sobretudo, as consequências do deslocamento do centro dinâmico de uma economia essencialmente agrária para uma economia urbana e industrial.

Palavras-chave: Desenvolvimento. Migração. População.

\section{Introdução}

O meio rural sempre esteve presente nas discussões sobre o desenvolvimento, por sua participação econômica, pela organização da sua matriz produtiva ou ainda devido aos entraves que a atividade possa representar para o restante da economia. No Brasil, desde os anos 1930, essas discussões estiveram estreitamente ligadas a um projeto de desenvolvimento associado à ideia de crescimento e progresso econômico. A atividade econômica rural era vista como condição necessária e suficiente para melhorar o

Doutora em Desenvolvimento Rural pela Univer-
sidade Federal do Rio Grande do Sul, Brasil. Pro-
fessora do Programa de Pós-Graduação em Desen-
volvimento Rural e do Programa de Pós-Graduação
em Práticas Socioculturais e Desenvolvimento So-
cial da Universidade de Cruz Alta, Brasil.

Recebido em 01/04/2016 - Aprovado em 01/09/2016 http://dx.doi.org/10.5335/hdtv.16n.2.6929 
bem-estar social e econômico da população, uma proposta que imitava o processo de industrialização e urbanização dos países desenvolvidos e suas teorias desenvolvimentistas, que, por meio de suas experiências empíricas, sugerem a aplicação de seus modelos aos países em desenvolvimento e subdesenvolvidos. Para Buarque,

[...] ao longo de décadas, os governos deram subsídios às indústrias e às cidades, ao mesmo tempo que abandonavam o campo à própria sorte, salvo nos aspectos que visavam substituir importações ou ampliar exportações (1994, p. 25).

É exatamente nesse aspecto que a questão envolvendo o desenvolvimento (entendido como progresso) e o meio rural torna-se ponto de discussão acadêmica e política no Brasil, a partir do final da década de 1950, e tem como base de análise a economia brasileira desde a época colonial e sua dependência do bom desempenho das exportações agrícolas. Posteriormente, várias discussões acadêmicas procuram interpretar o Brasil, tendo como pano de fundo essa discussão sobre os rumos do desenvolvimento, sendo a questão populacional (as causas da pobreza rural e o êxodo rural) o ponto central nesse debate.

Essas interpretações seguem algumas correntes de pensamento econômico sobre o desenvolvimento e colocam o crescimento da agricultura como alavanca ou como empecilho de desenvolvimento econômico, principalmente, os modelos de crescimento da corrente clássica e neoclássica, sobre as quais o debate sobre o desenvolvimento no Brasil se inicia. Para os economistas neoclássicos, a diminuição da população rural resulta naturalmente das oportunidades no meio urbano e ocasiona benefícios no meio rural. Segundo Romeiro (1991), a saída de trabalhadores do campo aumenta os salários do meio rural, o que estimula a modernização agrícola. Nos países desenvolvidos, o êxodo rural foi equilibrado, os fatores de atração para as cidades foram mais importantes do que os fatores de expulsão do campo. Segundo Gremaud et al.:

Falhas e restrições nesse setor não permitem que esse processo se desenvolva com o ritmo desejado, para que se atinjam os objetivos do desenvolvimento na extensão e nos prazos almejados pela sociedade (2003, p. 223).

Como também é responsável pela manutenção do desenvolvimento, por meio da oferta de produtos no mesmo ritmo da demanda e na mesma medida, o produtor precisa fazer frente a essa dificuldade, alterando seu modo e técnicas de produção.

As discussões recentes estão embutidas de uma percepção de que não é possível alcançar o desenvolvimento alicerçando-se nesse modelo e que a noção de crescimento e progresso é insuficiente para dar conta das transformações estruturais na agricultura brasileira. As limitações dessa concepção sobre o desenvolvimento são questionadas por Buarque:

[...] discurso acadêmico ficou imoral, porque legitima a desigualdade; incompetente, porque não descreve o real; e hipócrita, porque não assume essas duas características (1994, p. 69).

Este estudo procura fazer uma discussão sobre o desenvolvimento, buscando compreender que o meio rural está envolvido, de todas as formas, nesse debate, e não 
tem o objetivo de discutir as várias teorias sobre desenvolvimento. $\mathrm{O}$ desenvolvimento que será percebido aqui, e por grande parte da literatura sobre o tema, é o que proporciona melhoria nas condições de vida da população rural e urbana, condições que incluem, entre outros aspectos, os econômicos e sociais, sobretudo os aspectos demográficos.

Asssim, um dos aspectos analisados será a questão demográfica que permeia a discussão sobre o desenvolvimento e, principalmente, a redução da população rural e o processo migratório. Da mesma forma, os conceitos que surgem a partir dessa discussão, envolvem a temática meio rural e desenvolvimento. Na sequência, discute-se o aspecto demográfico nesse contexto e o processo migratório, enfatizando o contexto brasileiro.

\section{Aspecto demográfico, migração e desenvolvimento agrícola}

A relação entre o aumento do contingente populacional e a atividade agrícola está implícita e diretamente ligada ao espaço agrícola, que nada mais é do que o conjunto de relações entre a população rural, a terra por ela trabalhada e o produto desse trabalho. O espaço agrícola é descrito por Pierre George como um fato da geografia humana por resultar de uma ação voluntária diferencial do grupo humano em relação a um espaço já ocupado por uma vegetação natural.

Trata-se então da substituição de um meio biológico com pouco ou nenhum valor de utilização para o homem por um meio biológico útil. [...] uma mutação dos processos vitais que promovem a reprodução e a multiplicação das espécies (GEORGE, 1982, p. 19).
Segundo Albuquerque e Nicol (1987, p. 2), a atividade agrícola passou por vários estágios, contribuindo em maior ou menor proporção para o aumento da população e seu movimento migratório, principalmente o rural. Mesmo sendo o desenvolvimento da agricultura um dos fatores que interferem no aumento ou na diminuição da população, essa variação dependerá de outras condições sociais e culturais.

Se, em todo caso, o volume da produção agrícola limita forçosamente o número de homens, acontece que um aumento da produção agrícola não é suficiente, por si só, para conduzir ao aumento da população. Para isso, é preciso ainda que muitas outras condições sociais e culturais que comandam a natalidade e a mortalidade sejam realizadas. Mas para que uma população possa aumentar, ou mesmo simplesmente se renovar, é preciso, sobretudo, que a produção de um trabalhador agrícola, isto é, a produtividade do trabalho agrícola, seja pelo menos igual à soma de suas próprias necessidades e das necessidades de todos aqueles que ele deve alimentar. De fato, não se pode esquecer que em uma sociedade qualquer que seja a maioria dos indivíduos (velhos, crianças, deficientes, pessoas que possuem outras atividades que a de agricultor etc.) não produz sua própria alimentação (MAZOYER; ROUDART, 1998, p. 95).

Segundo George (1982, p. 63), no século XX, o mundo era essencialmente rural e mais da metade da população retirava da atividade agrícola seu meio de vida, não havendo lugar nesse meio para quem não retirasse da terra seu sustento, principalmene, nos países subdesenvolvidos. Na mesma obra, o autor define população rural como sendo aquela que compreende todos os indi- 
víduos que compõem a população agrícola, comerciantes e os que não estão disponíveis para o trabalho pela idade ou por alguma outra limitação.

Devido à interferência do desenvolvimento agrícola no aumento e na distribuição da população mundial nos séculos XIX e XX, nos países mais desenvolvidos, a expansão populacional foi acentuada, mas acompanhada de medidas econômicas e sociais que, ao reduzir a taxa de mortalidade, melhoraram as condições de vida da população, que cresceu de forma moderada. Por outro lado, nos países subdesenvolvidos, a população cresceu de forma desgovernada. Sobre o crescimento populacional nos países subdesenvolvidos, Rossetti (1978, p. 443) afirma que a aceleração do crescimento demográfico no pós-guerra atinge, sobretudo, áreas como Ásia, África e América Latina. Ainda segundo o autor, de 1950 até 1960, a população mundial cresceu em 500 milhões de habitantes, passando de 2,5 bilhões para 3 bilhões; $80 \%$ desse crescimento ocorreu em países subdesenvolvidos, esse índice repetiu-se nos anos subsequentes.

\section{Os movimentos migratórios agrários}

O processo de migração, segundo Sandroni (1999, p. 389), é um movimento populacional que se dirige de uma região (área de emigração) para outra (área de imigração). Esse movimento é considerado a base da dinâmica populacional, tanto quanto a natalidade e a mortalidade. O autor faz a distinção entre migração internacional (entre países) e migração interna (dentro das fronteiras de um mesmo país). A migração geralmente ocorre porque as pessoas não encontram oportunidades sociais e econômicas em seus locais de origem. Já o êxodo, seria uma aceleração da migração.

Segundo informe da Organização das Nações Unidas,

[...] a mobilidade da população no espaço, ou mobilidade geográfica, representada pela componente migração, é um tema diretamente relacionado à realidade humana (1980, p. 319).

Os movimentos migratórios estão relacionados com a própria existência do homem e a procura por melhores condições de vida.

Ilha Neto (1999, p. 18) denomina as primeiras migrações humanas de "primitivas" e foram responsáveis pela redefinição de funções sociais da família agrária. Essas migrações foram resultado de expulsões ecológicas devido à inabilidade do homem em lutar contra as forças naturais e por não dispor de meios técnicos para isso. No entando, a partir do momento em que esses meios ficaram disponíveis, o processo migratório ocorre, porém, com migrações em massa. Segundo o autor, a pressão da modernidade agrícola interfere nas transformações e decisões individuais das famílias agrícolas europeias, principalmente nas jovens rurais solteiras que procuram libertar-se dos controles familiares, deixando o meio rural e procurando trabalho assalariado no meio urbano, dificultando a reprodução das famílias camponesas e contribuindo para a expansão da população urbana.

Devido aos períodos de guerra no final do século XVIII e a Revolução Industrial que se iniciava no continente europeu, parte da mão de obra do meio rural é substituí- 
da por equipamentos agrícolas, mesmo que rudimentares, como arados e semeadeiras, ocasionando êxodo rural e acentuando o processo migratório mundial. Fusfeld (2001) afirma que com esse processo de modernização agrícola incipiente, algumas regiões passam a receber parte dessa população procedente do meio rural.

O processo migratório que ocorre por expulsão e/ou por atração acarreta mudanças significativas na composição da população. Na Ásia, mesmo antes do início da Revolução Industrial, a preocupação com a migração fez com que fossem criados mecanismos para prevenir a aceleração da migração rural-urbana e o êxodo rural. Segundo Verriére:

Sem esperar a maturidade industrial, os chineses chegaram até a organizar o êxodo urbano, a partir de Pequin e Xangai, o resultado mais eficiente desta iniciativa foi prevenir o êxodo rural pela oganização de Comunas Populares Rurais, que associam à agricultura, múltiplas atividades industriais, assim se evita a divisão das atividades que alimentam as emigrações rurais e favorecem ao dualismo rural-urbano (1980, p. 75).

Com o avanço do transporte, o desenvolvimento agrícola, as crises e guerras desaparece grande parte da população rural, principalmente na Inglaterra. Mazoyer e Roudart também descrevem esse contexto:

[...] desapareceu a maior parte do pequeno campesinato inglês (os yeomen), reduzido ao regime de assalariamento agrícola, à mendicância, ao êxodo para as cidades, ao regime salarial industrial ou à emigração para as colônias de povoamento. Na metade do século XIX, devido a esse vasto movimento de apropriação e de concentração fundiária, uma grande parte da terra se encontrava nas mãos de um número reduzido de grandes proprietários (os landlords): 2.000 dentre eles possuíam vastas propriedades que iam de 100.000 ha a 400.000 ha, que no total equivaliam a um terço do país, e onde existiam cerca de 200.000 explorações do tipo de residências senhoriais (1998, p. 384).

O desenvolvimento dos meios de transporte encurtou as distâncias entre os países, o que facilitou a migração, aumentando mundialmente as fronteiras agrícolas, conforme afirma Jonhson:

Com o advento do progresso dos transportes, no século XIX emigraram da Europa mais de 50 milhões de pessoas em direção à América do Norte. Muitos destes europeus se estabeleceram a leste da América do Norte, uma das regiões mais densamente populosas do mundo. Tal fato se deve às condições topográficas para implementar a agricultura, aumentando assim as fronteiras agrícolas do planeta (1971, p. 62).

Assim, o continente americano recebe um contigente significativo da população excedente do meio rural, principalmente europeia, que expandiu a colonização inglesa na América do Norte e de espanhóis e portugueses na América do Sul. Encontrando condições favoráveis para atividade agrícola, uma parte desses imigrantes continuou suas atividades, agora em outras áreas e sob outras condições, povoando essas terras. As populações primitivas do continente foram dominadas, pois a forma de vida dos povos nativos não interessava aos imigrantes europeus. Esse é considerado o maior movimento migratório da história. Outros movimentos foram dos hindus para a África, de chineses 
para a Malásia e de europeus para a Austrália e África. Para Furtado (2003, p. 11), a ocupação econômica das terras americanas constitui um episódio da expansão comercial da Europa, diferente do que ocorrera na Grécia, por exemplo, onde o processo migratório ocorreu por pressão demográfica.

\section{Movimentos migratórios no Brasil Colônia e Imperial}

As quantificações demográficas no início da ocupação brasileira são de difícil mensuração. Antes da transferência da Corte portuguesa para o Brasil (1808), a imigração restringia-se a escravos (forçosamente trazidos), pois os portugueses não eram considerados imigrantes em sua própria colônia. Com relação à ocupação brasileira, com esse contingente populacional oriundo do continente europeu, juntamente com a Corte portuguesa, Furtado (2003) afirma que foi por fatores de atração, e não de expulsão. $\mathrm{O}$ êxito da grande empresa agrícola açucareira constituiu, portanto, a razão de ser da continuidade da presença dos portugueses em uma grande extensão das terras brasileiras, e a introdução do modo de produção escravista, baseado na importação e escravização de africanos, que eram trazidos ao Brasil por portugueses e outros comerciantes que tivessem boas relações com Portugal, levando açúcar e trazendo negros para o Brasil. Segundo o autor, na região açucareira, os imigrantes regulares limitavam-se a artesãos e trabalhadores especializados que vinham diretamente para trabalhar nos engenhos. Se essa atividade resulta em migração de pessoas de outros lugares do país, também foi por causa deste produto, o açúcar, que a economia nordestina sofreu um lento processo de atrofiamento, no sentido de que a renda real per capita de sua população declinou, pois quanto menos favoráveis eram as condições da economia açucareira, maior era a tendência imigratória para o interior. Essa população encontra guarida na atividade pecuária, levando o povoamento do litoral para o interior, tanto de imigrantes nordestinos como de escravos.

No início do século XVIII, a economia extrativa do ouro constitui a atividade que mais atraiu imigrantes, mobilizando pessoas de outras regiões do país e, principalmente, de Portugal para a região de Minas Gerais. A influência do ciclo da mineração foi decisiva para o crescimento demográfico. A atividade exigia crescente utilização de mão de obra, e não teria sido possível sem os colonos e escravos africanos imigrantes. Para Furtado (2003), a economia mineira abriu um ciclo migratório europeu totalmente novo para a colônia, possibilitando acesso a pessoas de recursos limitados, pois não eram exploradas grandes minas, mas o metal de aluvião que se encontrava depositado no fundo dos rios. Segundo o autor, não se conhecem dados precisos sobre o volume da corrente emigratória que, das ilhas do Atlântico e do território português, formou-se em direção ao Brasil, no correr do século XVIII. Mesmo com as medidas tomadas por Portugal para dificultar o fluxo migratório, tudo indica que a população colonial de origem portuguesa decuplicou no correr do século da mineração. Esse processo migratório foi diferente do ocorrido no Nordeste, com a economia açucareira, pois na atividade mineradora os 
imigrantes financiavam sua transferência e o papel do escravo também era diferenciado, conforme sugere o autor:

Cabe admitir, demais, que o financiamento dessa transferência de população em boa medida foi feito pelos próprios imigrantes, os quais eram pessoas de pequenas posses que liquidavam seus bens na ilusão de alcançar rapidamente uma fortuna no novo eldorado. Se bem que a base da economia mineira também seja o trabalho escravo, por sua organização geral ela se diferencia amplamente da economia açucareira. Os escravos em nenhum momento chegam a constituir a maioria da população. Por outro lado, a forma como se organiza o trabalho permite que o escravo tenha maior iniciativa e que circule num meio social mais complexo. Muitos escravos chegam mesmo a trabalhar por conta própria, comprometendo-se a pagar periodicamente uma quantia fixa a seu dono, o que lhes abre a possibilidade de comprar a própria liberdade. Esta simples possibilidade deveria constituir um fator altamente favorável ao seu desenvolvimento mental (FURTADO, 2003, p. 81).

Na segunda metade do século XVIII, renasce a agricultura de exportação no Nordeste, especialmente com o aumento na produção do algodão no Maranhão, em Pernambuco e na Bahia. O desenvolvimento da cultura algodoeira, nos primeiros decênios do século, havia permitido uma diversificação da atividade econômica, o que contribuíra para intensificar o crescimento da população e sua manutenção na região. Em 1785, foi assinado, pela rainha Dona Maria, um decreto que determinou a extinção de todos os teares do Brasil e multas severas para quem desafiasse as leis, encerrando-se assim, mais um ciclo da economia brasileira e um novo ciclo emigratório da região Nordeste.

Outro grande movimento migratório da população ocorreu no final do século XIX e nos primeiros anos do século XX. A extração da borracha firmou-se como importante atividade exportadora (com a difusão do automóvel, aumenta o consumo de pneus). A expansão da atividade da borracha provoca uma grande afluência de pessoas do Nordeste para a Amazônia, projetando cidades como Belém e Manaus. Os governos dos estados amazônicos interessados organizaram serviços de propaganda e concederam subsídios para gastos de transporte, estadia e alimentação. Formou-se, assim, a grande corrente migratória, principal e novamente nordestina, que fez possível a expansão da produção de borracha na região amazônica.

O Brasil tornou-se dependente da migração para viabilizar suas atividades econômicas, desde seu descobrimento. Não foi diferente com a atividade cafeeira que passou a constituir um novo ciclo e uma nova forma de interferência na corrente migratória. No último decênio do século XIX, criou-se uma situação excepcionalmente favorável à expansão da cultura do café no Brasil, devido a problemas na oferta de outros países, como a produção asiática, por exemplo. O contexto agora é diferente, pois esses imigrantes vieram ocupar um espaço que poderia ter sido pelo reservatório substancial de mão de obra nordestina, que seria então aproveitado na atividade da borracha.

Segundo Bacha (2004), durante a segunda metade do século XIX, a atividade cafeicultora foi uma grande absorvedora de mão de obra, parte significativa do processo 
de migração estrangeira em direção ao Brasil ocorreu devido ao crescimento dessa atividade. Por um lado, os emigrantes foram expulsos devido às crises políticas e excedente populacional em seu país de origem, por outro, havia os fatores de atração, com as possibilidades de emprego na atividade cafeicultora no Brasil. Alguns desses imigrantes vieram diretamente residir na cidade, outros vieram residir no meio rural, quando venciam seus contratos de trabalho ou quando ocorria superprodução de café, migravam em direção à cidade. "Entre 1827 e 1929, entraram no Brasil 2,1 milhões de imigrantes, dos quais $90 \%$ no período de 1890 a 1914, ou seja, no período logo após a abolição da escravatura" (BACHA, 2004, p.123).

Assim, a imigração estrangeira exerceu um impacto importante para a região Sudeste e para os estados do Sul, na segunda metade do século XIX e nas duas primeiras décadas do século XX. Segundo Baer (1996, p. 294), no caso de São Paulo, a imigração estava ligada à expansão do setor cafeeiro e no Sul, ao desbravamento de novas terras nas quais, após a exploração de produtos da floresta, desenvolveu-se uma agricultura comercial que atendia aos mercados urbanos em crescimento. Depois disso, a migração assumiu uma importância cada vez maior, especialmente quando a industrialização com vistas à substituição de importações tornou-se a principal força dinâmica da economia, melhorando as comunicações entre as várias regiões do país e, localizada no Sudeste, atraiu um significativo número de migrantes. Ainda assim, é provável que essa imigração não houvesse alcançado níveis tão elevados não fora um conjunto de condições favoráveis do lado da oferta.

Furtado explica como ocorreu essa oferta de mão de obra imigrante italiana e as bases para a formação da grande corrente imigratória que tornaria possível a expansão da produção cafeeira no estado de São Paulo. Segundo ele, durante a mesma época em que evoluía a necessidade de mão de obra para a atividade cafeeira no Brasil, a região sul da Itália, de menor grau de desenvolvimento e com mais baixa produtividade agrícola, encontrou-se em difícil situação para enfrentar a concorrência das regiões mais desenvolvidas do norte, devido à unificação ocorrida no século XIX. A solução foi a migração

[...] como verdadeira válvula de alívio [...]. O número de imigrantes europeus que entram nesse estado sobe de 13 mil, nos anos 70, para 184 mil no decênio seguinte e 609 mil no último decênio do século. $O$ total para o último quartel do século XIX foi 803 mil, sendo 577 mil provenientes da Itália (FURTADO, 2003, p. 134).

Um comparativo no processo migratório entre os migrantes do café e os da borracha faz com que Furtado (2003) aponte evidentes particularidades e contrastes entre os dois movimentos migratórios, que resultaria do desenvolvimento subsequente diferenciado das duas regiões. A região onde predominava a economia cafeeira, em meio século de altos e baixos, demonstrar-se-ia ser suficientemente sólida, levando ao desenvolvimento de um processo de industrialização, e seus imigrantes teriam em nível de vida relativamente mais elevado do que de onde haviam migrado. A economia da borracha, ao contrário, entraria em 
brusca e permanente prostração, e a população imigrante teria condições de vida ainda mais precárias daquelas que haviam conhecido em sua região de origem.

$\mathrm{Na}$ sociedade brasileira, os movimentos populacionais ocorridos em diferentes momentos da sua história influenciaram sua formação econômica, sua estrutura social e na constituição da mão de obra. Durante os períodos colonial e imperial, a principal mão de obra utilizada na agricultura brasileira era a escrava, importada principalmente do continente africano, do qual eram trazidos à força, muitas vezes, enganados por falsas promessas de terem uma vida mais digna. Inicialmente, tentou-se o uso do indígena como escravo, mas essa experiência não foi bem sucedida em todas as províncias do país devido à dificuldade em dominá-los. Essa população drasticamente diminuiu devido ao enfrentamento com colonizadores, às doenças $\mathrm{e}$, muitas vezes, pelo trabalho forçado. Posteriormente, a migração europeia preencheu as necessidades de mão de obra. Assim, pode-se afirmar que a rápida expansão da população brasileira deveu-se, em grande parte, à imigração. Segundo dados do Instituto Brasileiro de Geografia e Estatística, o censo geral de 1872, quando da contagem da população que vivia no Brasil, aponta para 9.930.478 pessoas; já em 1890 esse número sobe para 14.333.195, ou seja, um aumento de $44 \%$. Desses, 1.129 .317 eram imigrantes.

Segundo Sandroni "no final do século XIX, quando a imigração estrangeira se acentuou, grande parte foi encaminhada para as lavouras de café paulistas, então em grande expansão" (1999, p. 389). O deslo- camento de mão de obra de um lugar para outro foi provocado pelos diversos ciclos econômicos. A fragilidade de alguns ciclos, como o da borracha e o do ouro, por exemplo, impossibilitou a fixação na terra, muitas vezes, em decorrência do isolamento dos centros econômicos. Dessa forma, as migrações internas são o resultado da procura por melhores condições de vida. Para Buescu e Tapajós (1958) os subciclos também tiveram importância nas migrações no Brasil, principalmente as internas, como o subciclo do gado, que foi responsável pela movimentação de populações do Nordeste, tanto em direção ao Norte quanto para o Sul e Sudoeste.

\section{Movimentos migratórios no Brasil República}

Durante a República Velha, foi proibida a entrada de imigrantes considerados "indesejados", o que se pode verificar também na Constituição de 1934 e nas Constituições seguintes, que estabelecem rigorosas normas para a entrada de imigrantes no território nacional, com o objetivo de proteger o emprego dos trabalhadores brasileiros. Da mesma forma, pode-se dizer que um marco temporal para o estudo da migração interna no Brasil foi o ano de 1930, devido, principalmente, à seca do Nordeste, à urbanização, à crise da atividade cafeeira e à industrialização. O modelo urbano-industrial adotado a partir da falência do modelo agrário-exportador, explica o desenvolvimento urbano ocorrido em quase todo o país, em detrimento do setor rural, considerado tradicional e desorganizado. Martins (1975, 
p. 13) chama a atenção que o processo de imigração interna provocou a "ideologia urbana" que se contrapõe à vida rural. O propósito dessa ideologia era tranformar o caipira "ingênuo, preguiçoso, desnutrido, doente" em cidadão urbano.

A urbanização tem suas raízes na crise de 1929 e na Grande Depressão mundial, ao mudar a dinâmica da economia brasileira que passa a repensar sua economia interna e o desenvolvimento da incipiente industrialização iniciada pela cafeicultura. Para Graziano da Silva (1998), a agricultura, no entanto, permanecia atrelada àquelas velhas formas latifundiárias do Norte e do Nordeste do país. De forma diferente, a agricultura paulista transforma-se em elemento dinâmico e dá um salto de diversificação na década de 1930, sobretudo com cultura de algodão e açúcar, saindo renovada da crise.

A crise da economia cafeeira causada pela expansão desordenada e acelerada do café, pela queda na demanda e nos preços devido à crise da economia mundial, ocasionou um crescimento na oferta muito superior ao crescimento de sua demanda. Os imigrantes, que eram na maioria italianos, portugueses, espanhóis e alemães, terminados os contratos que os prendiam à terra, estabeleciam-se nos grandes centros urbanos, criando um fluxo migratório rural-urbano. Assim, com a crise da atividade cafeeira, a absorção de mão de obra pela agricultura declina acentuadamente. Para Albuquerque e Nicol:

A partir daí começa a absorver proporcionalmente menos mão de obra, permitindo influxo de imigrantes para as cidades, aumentando a oferta de mão de obra para os novos setores (1987, p. 202).
De acordo com Bacha:

O período de 1930 até 1945 é marcado pela crise da cafeicultura e pela diversificação da pauta agrícola e incipiente industrialização. A partir da década de 1930/1939 a imigração estrangeira diminuiu em direção ao Brasil e iniciou-se um processo de migração rural-urbana. Esse processo acelerou-se na década em consideração devido a crise da cafeicultura, a qual liberou parte dos colonos empregados nesse setor. Essa mão de obra veio a constituir força de trabalho para os setores industriais e urbanos que então se desenvolviam (2004, p. 140-141).

Dessa forma, o país passou de uma economia centrada no setor rural para uma economia diversificada e direcionada mais diretamente para a atividade industrial, com a construção de um parque industrial próprio, havendo a substituição de importações. O processo de industrialização no Brasil ocorre principalmente a partir da Primeira Guerra Mundial e da Revolução de 1930. Consequentemente às dificuldades de importar produtos industrializados, o mercado interno criado pela atividade cafeeira e o capital oriundo da crise desse setor fazem com que o número de indústrias cresça significativamente nesse período. Esse parque industrial instala-se principalmente no estado de São Paulo, devido ao mercado consumidor construído pela atividade cafeeira, pela mão de obra livre e pela existência de capacidade instalada durante a década de 1920. Se até esse período a migração era da área rural para outra área rural para suprir a demanda de mão de obra durante os ciclos econômicos, a partir do processo de industrialização, as migrações se intensificam de áreas rurais 
para urbanas, principalmente, quando o trabalhador urbano passa a ter salário minímo, estabilidade e seguridade social e quando houve a adoção de uma política salarial diferenciada entre as regiões do país, de acordo com o seu grau de desenvolvimento.

A partir da década de 1950, intensifica-se a produção de bens duráveis, como automóveis e eletrodomésticos no país. Nesse período intensificam-se, também, os conflitos políticos no Brasil e fora dele, da mesma forma aumenta a discussão de que o desenvolvimento econômico deve ser liderado pela industrialização, e não pela agricultura, com base nas ideias cepalinas. Segundo Bacha, o setor agropecuário cresce apesar da discriminação, pois o fornecimento da mão de obra para a expansão industrial foi possível graças à migração campo-cidade.

Constata-se que no período de 1950 a 1960, por exemplo, cerca de 11 milhões de pessoas migraram das áreas rurais para as cidades, o que representou $32,6 \%$ da população rural existente em 1950 (BACHA, 2004, p. 151).

Dessa forma, o setor agropecuário contribuiu com o processo de industrialização fornecendo mão de obra, sem modificar seu processo de crescimento, que continua aumentando devido à utilização de novas terras dedicadas ao cultivo, em vez do aumento da produtividade em áreas agrícolas mais antigas.

O período seguinte, até a década de 1960, foi marcado pela aceleração do processo de modernização da agricultura brasileira, impulsionado por políticas direcionadas para o setor, importação de tecnologia de plantio e insumos agrícolas e remodelação do sistema cooperativista. À medida que a produção e a produtividade iam aumentan- do, da mesma forma aumentava o fluxo de pessoas que deixaram o meio rural em direção à cidade. Segundo Bacha:

No período de 1960/1970 houve migração anual média de 1,15 milhão de pessoas. No período de 1970/1980 essa migração foi de 1,44 milhão de pessoas por ano e no período de 1980/1990 ela foi de 1,21 milhão de pessoas por ano (2004, p. 169).

Dentre outros fatores, a criação do Estatuto do Trabalhador Rural (Lei $\mathrm{n}^{\circ} 4.214$, de 1963) foi, em parte, responsável pelo processo migratório. Esse instrumento, que objetivava equiparar os direitos dos trabalhadores rurais e urbanos na tentativa de melhorar o regime de trabalho no campo, desestimulou o vínculo empregatício e criou incentivos adicionais para que a mecanização, já apoiada por outras medidas de política agrícola, se tornasse ainda mais intensa. Era mais viável mecanizar as lavouras do que aumentar os custos com mão de obra e ter complicações trabalhistas decorrentes da contratação de trabalhadores, cuja utilização normalmente é sazonal e, sobretudo, enfraquecendo as formas de relacionamento proprietários-trabalhadores rurais.

Assim, o processo de modernização foi um dos fenômenos que mais alterou a fisionomia do meio rural e urbano no que diz respeito ao número da população e às relações de produção e trabalho, assumindo cada vez mais características de relações capitalistas. Delgado salienta que

[...] a modernização conservadora avançou como um caudal, erodindo barreiras, destruindo estruturas produtivas primitivas, concentrando os frutos do processo técnico, num movimento de profunda e historicamente acelerada rejeição do contingente primitivo de população rural (1985, p. 12). 
A modernização intensificou-se pela distribuição desigual da terra e de outros bens, com a manutenção e reforço da estrutura agrária concentrada, ou seja, foi justamente isso e o favorecimento das propriedades patronais que deram origem à expressão "modernização conservadora", que daria origem a esse processo. $\mathrm{O}$ termo foi cunhado devido à manutenção da estrutura agrária vigente e o favorecimento às propriedades patronais, que deram origem ao apelido utilizado pelos opositores desse processo.

Para Graziano da Silva, essa é uma característica fundamental da modernização da agricultura no Brasil, que tem características excludentes, tanto no tamanho das propriedades agrícolas, no tipo de produto, quanto na região, privilegiando os grandes e médios produtores de produtos voltados à exportação, geralmente integrados aos complexos agroindustriais, localizados predominantemente nas regiões Centro-Oeste, Sudeste e Sul do país.

Em nossa opinião, as forças que controlam essa corrida-ou seja, a adoção das inovações tecnológicas tenderá a acelerar a sua velocidade de transformação nos próximos anos. Com isso, eliminarão parte significativa desses produtores hoje ditos tecnificados, marginalizado-os dos complexos agroindustriais. $\mathrm{O}$ movimento compensatório de crescimento dos CAIS em outras atividades e outras regiões do país nada mais significará do que uma postergação dessa tendência. Com a difusão da modernização, ocorre a especialização da agricultura em escala nacional. Em algumas regiões desenvolveu-se e modernizou-se a produção de culturas que, embora presentes em economias familiares, são consideradas típicas de uma agricultura comercial. A estrutura fundiária evoluiu em um sen- tido concentrador e excludente, dificultando, qualquer tipo de acesso à terra, aos trabalhadores rurais brasileiros (GRAZIANO DA SILVA, 1982, p. 168).

Para Accarini (1987, p. 109), a modernização agrícola pode tomar duas direções principais: o aumento da produtividade da mão de obra, obtido, fundamentalmente, com o uso de tecnologias mecânicas como tratores, colheitadeiras, semeadeiras e muitos outros equipamentos e implementos mais aperfeiçoados, e o aumento da produtividade da terra, principalmente com o emprego de inovações biológico-químicas e métodos de produção mais aprimorados, como sementes e mudas mais produtivas, fertilizantes, defensivos e corretivos, além de novos métodos de preparo do solo, plantio e cultivo.

Porém, a modernização da agricultura brasileira adotada na década de 1960-1970 era voltada ao consumo de capital e tecnologia externa, facilitada pelo acesso ao crédito rural, determinantes para o endividamento e a dependência dos agricultores. Graziano da Silva (1982, p. 45) afirma que ao provocar desigualdade entre as regiões do país, entre as atividades agrícolas e entre os produtores rurais, provoca-se também o aumento da concentração da terra, que em muitos casos se dá pela sua utilização como reserva de valor ou especulação imobiliária, não necessariamente associada à sua utilização como meio de produção. Assim, a propriedade privada da terra contitui-se condição necessária, mas não suficiente, para a existência da renda. Delgado (1985) ressalta, ainda, que o processo intenso de urbanização pelo qual passou a economia brasileira no pe- 
ríodo da pós-modernização agrícola, enseja ainda uma valorização das terras agrícolas e do solo urbano também em ritmo acelerado, movimento que, em seu conjunto, propicia ganhos substanciais aos detentores de patrimônios imobiliários.

Os custos do ajustamento à modernização agrícola recaem, sobretudo, nos trabalhadores e produtores rurais menos capitalizados e qualificados, que ficam à margem da transformação que está ocorrendo na atividade agrícola ou se endividam para ajustarem-se a ela. Acrescentando-se a essas forças de expulsão, existe ainda a atração que as cidades exercem sobre o homem em termos de expectativas de emprego, oportunidades de acesso à saúde, educação, lazer e infraestrutura. Não raramente, esse conjunto de aspectos força um siginicativo número de pessoas a sair da atividade rural, ocasionando êxodo rural. Na afirmação de Graziano da Silva:

As cidades se tornaram uma esperança de acesso a saneamento, água encanada, luz elétrica, hospital, creche e escolas, de que o meio rural não dispõe. $O$ fracasso da tentativa de levar alguns desses beneficios ao campo, por exemplo, os custosos e ineficientes programas de eletrificação rural, ensino agrícola-reforçou ainda mais essa percepção. [...] Ou seja, esse pequeno produtor saiu do campo e veio para a cidade em busca de escola para os filhos e dos "confortos" da cidade. Na cidade, a família diversificou a origem de sua renda. Mas, ao contrário do que se esperava, os anos 80 não revelaram consolidação dessa tendência dos trabalhadores rurais de virem residir nas cidades (1982, p. 182).

Esse quadro de consequências da modernização resulta na concentração da pro- priedade da terra, na medida em que há a inviabilização econômica das pequenas propriedades, provocada, principalmente, pela falta de escala produtiva ou por endividamento, essas áreas de produção são adquiridas por outros agricultores, que assim aumentam seu patrimônio.

Na década de 1980, depois de quase vinte anos de controle político e uma sociedade marcada por problemas macroeconômicos, o setor agrário não ficou alheio a essas transformações, as políticas econômicas e setoriais específicas diminuem os estímulos à atividade agrícola. $\mathrm{O}$ processo de migração campo-cidade continuou após 1980, apesar da mão de obra rural já não ser fundamental para o processo de industrialização, como fora nos períodos anteriores. Assim, o contexto macroecônomico não favorece a esses imigrantes, e o jovem rural deixa de ser desempregado rural para tornar-se desempregado urbano.

No início dos anos 1990, novamente as discussões acerca do papel a ser desempenhado pela agricultura, e no contexto do desenvolvimento do meio rural e da economia brasileira, adquirem outra dimensão, ao discutir não somente a agricultura lato sensu, mas a agricultura familiar. Faz parte desse contexto e discussão, a criação do Programa Nacional de Fortalecimento da Agricultura Familiar em 1996.

No início do século XXI, o grau de urbanização da população brasileira aponta para uma redução absoluta e relativa do fluxo migratório rural-urbano, em comparação com o verificado nos anos 1960 e 1970. Uma das explicações estaria no fato de já ter ocorrido redução absoluta do estoque da popu- 
lação rural em outros períodos, além da forte queda na taxa de fecundidade registrada nos últimos anos.

\section{A mobilização da população agrícola contribuindo para alavancar os estágios de crescimento econômico no Brasil}

Nas primeiras décadas do século $X X$, o Brasil deveria cumprir certas etapas para se desenvolver. A Revolução de 1930 tem a premissa de encerrar a "etapa arcaica" da economia brasileira. Assim, para avançar nas próximas etapas do desenvolvimento, a força de trabalho agrícola seriar deslocada do setor primário para o secundário e desse para o terciário. Da mesma forma, o país deveria seguir um caminho a ser percorrido rumo à industrialização e urbanização, conforme já ocorrido em outros países, um modelo de crescimento baseado na teoria dos estágios de crescimento de Rostow (1971). Segundo o autor, sempre seria possível decompor a história e o processo de desenvolvimento econômico em etapas sucessivas e nelas enquadrar diferentes países de acordo com suas respectivas características estruturais. Essas fases seriam: sociedade tradicional, precondições para a decolagem (desenvolvimento autossustentado), a decolagem propriamente dita, a marcha para a maturidade e era do consumo em massa.

Na dinâmica de Rostow, sociedade tradicional é aquela cuja estrutura se expande dentro de funções de produção limitadas. As precondições para o arranco ocorrem com a industrialização, e da mesma forma a migração de trabalhadores do setor agrícola para o setor industrial, com o crescimento concentrando-se em um número reduzido de regiões do país e em poucas indústrias. No período do arranco difundem-se novas técnicas agrícolas e industriais, à medida que a agricultura vai sendo industrializada, aumenta a produtividade agrícola. A maturidade é percebida como a etapa em que a economia demonstra capacidade de avançar para além das indústrias que inicialmente lhe impeliram o arranco. Dentro desse processo dinâmico de alterações estruturais, caberia à agricultura desempenhar diferentes papéis, passando de um setor predominantemente tradicional para um segmento de dimensões cada vez menores, com o emprego de tecnologias cada vez mais modernas, à medida que novas etapas fossem sendo conquistadas.

Os modelos de Yujiro Hayami e Vernon Wesley Ruttan (1988) contribuem para a compreensão da direção e dinâmica do processo de modernização agrícola e para explicar o padrão tecnológico seguido por distintos países e em diferentes épocas no estágio de desenvolvimento em estudos empíricos desenvolvidos nos Estados Unidos e no Japão. O modelo de inovação induzida, proposto pelos autores, pode representar quais as possíveis direções do desenvolvimento agrícola. A teoria considera a tecnologia como variável poupadora no uso de fatores escassos e intensifica o uso dos fatores abundantes na atividade agrícola. Hayami e Ruttan entendem que o principal objetivo do desenvolvimento agrícola é o de acelerar

[...] a taxa de crescimento da produção e produtividade agrícolas, compatíveis com o crescimento de outros setores de uma economia em vias de modernização (1988, p. 47-48). 
O modelo serviu de base teórica para a modernização da atividade agrícola no Brasil.

Em virtude desse modelo adotado no Brasil, Pastore, Dias e Castro (1976) apontam desigualdades regionais e a concentração geográfica da produção e a presença de mercados consumidores mais exigentes - o que ocorre com as matérias-primas processadas pelas indústrias e com os produtos de exportação. Schultz (1964) explica as diferenças regionais no grau de desenvolvimento da agricultura. Sua hipótese principal era de que os segmentos rurais localizados mais favoravelmente em relação aos centros urbanos reuniam melhores condições para se desenvolverem por meio da comercialização e aquisição de insumos, enfatizando a importância da agricultura exportadora para o desenvolvimento regional. Os estudos de Schultz afirmam que para viabilizar a proposta de transformar a agricultura e promover o desenvolvimento rural, seria necessário investir em pesquisa e gerar conhecimentos tecnológicos que propiciassem expressivos retornos econômicos, conhecimentos que deveriam ser transformados em insumos modernos e desenvolvidos pelo setor industrial.

Assim, é consenso entre os autores que no processo de desenvolvimento econômico e agrícola uma das tendências é a redução da população rural em relação à urbana. Para Accarini, "o que é possível através do emprego de tecnologias que direta ou indiretamente aumentam a produtividade da força de trabalho que permanece no campo" (1987, p. 41). As consequências dessa redução de pessoas nas áreas rurais são analisadas também por Singer (1983, p. 231). No en- tanto, segundo ele, não necessariamente esse processo de redução traduz-se em desenvolvimento econômico. Um dos motivos é que nem sempre os migrantes conseguem emprego no meio urbano e os que conseguem se inserir no mercado de trabalho remetem parte dos seus ganhos para os familiares que permaneceram nas áreas de economia de subsistência ou em outras áreas. E esses recursos serão utilizados para a compra de produtos da economia local, reduzindo o volume da demanda efetiva da cidade. Da mesma forma, Martins (1986) enfatiza que o desenvolvimento positivo de uma sociedade está diretamente ligado à urbanização, até porque as pessoas que residem no meio rural são mais condescendentes com a saída de seus membros da comunidade do que com a entrada de pessoas vindas das cidades e de outras ocupações.

Para Tambara (1985, p. 75), quanto à urbanização, frequentemente utilizada como indicador de desenvolvimento, a priori não se pode dizer que é um fato bom ou ruim. Tomando-se por base as sociedades mais desenvolvidas, como as europeias e a norte-americana, a urbanização seria positiva para o desenvolvimento, desde que essas tenham condições de acolher a população migrante, pois, por um lado, nos fatores de expulsão do indivíduo de seu local de trabalho estão presentes a estagnação das áreas agrícolas e as mudanças tecnológicas, nos fatores de atração os elementos fundamentais estão ligados à melhoria do nível de vida e ao lado funcional vinculado ao aspecto profissional. Entretanto, ressalta-se que essa divisão é utilizada mais com finalidade acadêmico-didática e não encontra muito 
respaldo na realidade, em que os fatores na verdade se interrelacionam.

Na prática, contudo, nessa evolução "desejável" e "natural" do rural para o urbano no processo de desenvolvimento, a mecanização agrícola muito intensa libera número excessivo de trabalhadores, ou porque os próprios trabalhadores despreparados para essa nova realidade deixam o meio rural à procura de outras atividades, ou porque suas atribuições não são mais necessárias. Em ambos os casos, que podem ocorrer conjuntamente, o resultado é, normalmente, a transferência de mão de obra pouco qualificada e em razão do baixo nível educacional, além de outros problemas sociais que provavelmente ocorrerão nesse novo contexto.

\section{Considerações finais}

Na sociedade brasileira, impulsionados pelos ciclos econômicos, os movimentos populacionais ocorridos em diferentes momentos de sua história influenciaram na sua formação econômica e estrutura social. Assim, o Brasil tornou-se dependente da migração para viabilizar seus ciclos econômicos, desde seu descobrimento.

A partir do processo de industrialização, as migrações intensificam-se de áreas rurais para urbanas, principalmente quando o trabalhador urbano passa a ter salário minímo, estabilidade e seguridade social e a adoção de uma política salarial diferenciada entre as regiões do país, de acordo com o seu grau de desenvolvimento. O período da modernização agrícola, que se acentua a partir de 1960, aliado à criação do Estatuto do Trabalhador Rural, aumenta o fluxo de pessoas que deixam o meio rural em direção à cidade.

O processo de migração do meio rural continuou após 1980, apesar de a mão de obra rural já não ser fundamental para o processo de industrialização. No início dos anos 1990, as discussões acerca do papel a ser desempenhado pela agricultura adquirem outra dimensão, a agricultura familiar.

No início do século XXI, o grau de urbanização da população brasileira aponta para uma redução absoluta e relativa do fluxo migratório rural-urbano. Uma das explicações estaria no fato de já ter ocorrido redução absoluta do estoque da população rural em outros períodos, além da forte queda na taxa de fecundidade registrada nos últimos anos.

A discussão sobre a temática da diminuição da população rural tem início no período que precede as políticas nacional-desenvolvimentistas e do esgotamento do modelo agroexportador brasileiro baseado no café, estudando, sobretudo, as consequências do deslocamento do centro dinâmico de uma economia essencialmente agrária para uma economia urbana e industrial. Porém, é a partir do final de 1970 e, principalmente na década de 1980, que esse tema passa a ser amplamente discutido, tendo como fio condutor a modernização agrícola e o êxodo rural.

$\mathrm{Na}$ discussão sobre o meio rural e as interfaces do desenvolvimento, parece transparecer de maneira mais precisa que uma das funções mais importantes da agricultura no território é a de manter ou pro- 
porcionar à população rural qualidade de vida. Também a produção agrícola pode ter um efeito sobre o desenvolvimento do território, por seu impacto econômico e também pelos reflexos que recaem sobre os outros setores da economia, dinamizando-os ou retraindo-os.

A manutenção da qualidade de vida nem sempre é possível no meio rural ou na atividade agrícola, o que faz com que muitos agricultores abandonem suas atividades ou o meio rural, na expectativa de melhores condições de vida, provocando mobilidade, migração e até mesmo êxodo.

\section{Abstract}

The countryside has always been present in the discussions on the development, through their economic participation or organization of their productive matrix, or the barriers that it may pose to the rest of the economy. In this study, we discuss the demographic aspect of this and the migratory process, emphasizing the Brazilian context. It can be said that the discussion on the issue of decreasing rural population starts in the period preceding the national-developmentalist and the agro-export the coffee-based Brazilian model depletion policies, studying mainly offset the consequences of the dynamic center of a primarily agrarian economy to an urban, industrial economy.

Keywords: Development. Migration. Population.

\section{Resumen}

El campo ha estado siempre presente en los debates sobre el desarrollo, a través de su participación económica u organización de su matriz productiva, o las barreras que puede suponer para el resto de la economía. En este estudio, se discute el aspecto demográfico de esta y el proceso migratorio, haciendo hincapié en el contexto brasileño. Se puede decir que la discusión sobre la cuestión de la disminución de la población rural se inicia en el período anterior a la nacional-desarrollista y la agroexportación las políticas de agotamiento modelo brasileño a base de café, estudiando principalmente compensar las consecuencias del centro dinámico de un economía fundamentalmente agraria a una economía industrial urbana.

Palabras clave: Desarrollo. Migración. Población.

\section{Referências}

ACCARINI, José Honório. Economia rural e desenvolvimento: reflexões sobre o caso brasileiro. Petrópolis: Vozes, 1987. 224 p.

ALBUQUERQUE, Marcos Cintra C.; NICOL, Robert. Economia agrícola: o setor primário e a evolução da economia brasileira. São Paulo: McGraw-Hill, 1987. 335 p.

BACHA, Carlos José Caetano. Economia e política agrícola no Brasil. São Paulo: Atlas, 2004. $226 \mathrm{p}$.

BAER, Werner. A economia brasileira. São Paulo: Nobel, 1996. 416 p. 
BUARQUE, Cristovam. A revolução nas prioridades: da modernidade técnica à modernidade ética. São Paulo: Paz e Terra, 1994. 287 p.

BUESCU, Mircea; TAPAJÓS, Vicente. História do desenvolvimento econômico do Brasil. Rio de Janeiro: A Casa do Livro, 1958. 204 p.

DELGADO, Guilherme Costa. Capital financeiro e agricultura no Brasil: 1965-1985. São Paulo: Ícone, 1985. $240 \mathrm{p}$.

FURTADO, Celso. Formação econômica do Brasil. 32. ed. São Paulo: Nacional, 2003. 256 p.

FUSFELD, Daniel R. A era do economista. São Paulo: Saraiva, 2001. 356 p.

GEORGE, Pierre. Geografia rural. São Paulo: Difel, 1982. $258 \mathrm{p}$.

GRAZIANO DA SILVA, José Francisco. A nova dinâmica da agricultura brasileira. São Paulo: Unicamp, 1998. 211 p.

GRAZIANO DA SILVA, José Francisco. A modernização dolorosa. Rio de Janeiro: Zahar, 1982. $192 \mathrm{p}$.

GREMAUD, Amauri Patrick (Org.). Agricultura e desenvolvimento econômico. Manual de economia. 4. ed. São Paulo: Saraiva, 2003. 606 p.

HAYAMI, Yujiro; RUTTAN, Vernon W. Desenvolvimento agrícola: teoria e experiências internacionais. Brasília: Embrapa, 1988.

ILHA NETO, Severo Francisco. Notas sobre a evolução da família agrária ocidental e sua desagregação na sociedade contemporânea. Cadernos de Extensão Rural, Santa Maria, v. 1, n. 15, p. 2-37, 1999.

JOHNSON, J. H. El hombre y la tierra. Londres: Aliança, 1971.

MARTINS, José de Souza. Capitalismo e tradicionalismo. São Paulo: Pioneira, 1975. 161 p.

. (Org.). Introdução crítica à sociologia rural. São Paulo: Hucitec, 1986. 224 p.

MAZOYER, Marcel; ROUDART, Laurence. História das agriculturas do mundo: do neolítico à crise contemporânea. Lisboa: Instituto Piaget, $1998.520 \mathrm{p}$.

ORGANIZAÇÃO DAS NAÇÕES UNIDAS. Conceitos básicos, definições e mensuração da migração interna. Fortaleza: Banco do Nordeste do Brasil, 1980.

PASTORE, José; DIAS, Guilherme L. da; CASTRO, Manoel Cabral de. Condicionantes da produtividade da pesquisa agrícola no Brasil. Estudos Econômicos, São Paulo, v. 6, n. 3, p. 147182, set./dez. 1976.

ROMEIRO, Ademar Ribeiro. Dinâmica de introdução de inovações na agricultura: uma critica a abordagem neoclássica. Revista de Economia Política, São Paulo, v. 11, n. 1, p. 43-55, 1991.

ROSSETTI, José Paschoal. Introdução à economia. 7. ed. São Paulo: Atlas, 1978. 812 p.

ROSTOW, Walt W. Etapas do desenvolvimento econômico. Rio de Janeiro: Zahar, 1971. 198 p.

SANDRONI, Paulo. Novíssimo Dicionário de Economia. São Paulo: Best Seller, 1999. 649 p.

SCHULTZ, Theodore W. Transforming traditional agriculture. New Haven; London: Yale University Press, 1964.

SINGER, Paul. Economia política urbanização. São Paulo: Brasiliense, 1983. 151 p.

TAMBARA, Elomar. RS: modernização \& crise na agricultura. Porto Alegre: Mercado Aberto, 1985. 95 p.

VERRIÉRE, Jacques. As políticas de população. São Paulo: Difel, 1980. 177 p. 